\title{
Slotted Hole Effect on Damage Mechanism of Gymnasium Building with RC Frame and Steel Roof
}

\author{
Atsushi Suzuki1 ${ }^{*}$, Tomomi Fujita², Yoshihiro Kimura ${ }^{3}$ \\ ${ }^{1}$ Oyu Tolgoi Project Team, Premium Industrial and Engineering LLC, Ulaanbaatar, Mongolia \\ ${ }^{2}$ Architectural Course, National Institute of Technology: Sendai College, Natori, Japan \\ ${ }^{3}$ Graduate School of Engineering, Tohoku University, Sendai, Japan \\ Email: *suzuki-at@acglobal.org
}

How to cite this paper: Suzuki, A., Fujita, T. and Kimura, Y. (2020) Slotted Hole Effect on Damage Mechanism of Gymnasium Building with RC Frame and Steel Roof. Open Journal of Civil Engineering, $10,162-174$.

https://doi.org/10.4236/ojce.2020.102014

Received: May 21, 2020

Accepted: June 20, 2020

Published: June 23, 2020

Copyright $\odot 2020$ by author(s) and Scientific Research Publishing Inc. This work is licensed under the Creative Commons Attribution International License (CC BY 4.0).

http://creativecommons.org/licenses/by/4.0/

\begin{abstract}
On the 2011 off the Pacific Coast of Tohoku Earthquake, gymnasium buildings exhibited the unexpected structural damages, which prevented a use as evacuation shelters in during- and post-disaster periods. The major failure occurring on the connection between the RC column top and steel roof as well as the cracks in the $\mathrm{RC}$ column base was observed during the emergent inspection. According to the earlier studies, it was implied that the presence of the slotted hole possibly deteriorates the seismic capacity; however, the length of slotted hole was fixed at a certain value. Facing this concern, this research attempts to clarify the influence of the slotted hole length through a comprehensive parametric study by pushover and seismic response analyses. In conclusion, it has been discovered that the slotted hole deteriorates the seismic capacity for the connection failure up to almost $50 \%$ of that without slotted hole. Moreover, the discrepancy of characteristics obtained by the static and dynamic analyses is originated by means of the presence of slotted hole. This slotted hole effect should be noted by structural engineers and researchers to provide the adequate seismic diagnosis and strengthening.
\end{abstract}

\section{Keywords}

RC Frame with Steel Roof Structure, The 2011 off the Pacific Coast of Tohoku Earthquake, Damage Mechanism, Pushover Analysis, Seismic Response Analysis

\section{Introduction}

The 2011 off the Pacific Coast of Tohoku Earthquake (hereinafter referred to as 
GEJET) stroke Tohoku region on March 11th in 2011. This mega-earthquake with the magnitude of 9.0 caused approximately 15,000 casualties and around 2,500 people are still missing. The main cause of their death was the tsunami followed by the strong shake, and the death caused by the building collapse was very little by virtue of the continuous efforts on the seismic diagnosis and strengthening [1].

In the meantime, the unique structural damage newly emerged in this earthquake. Particularly, the gymnasium buildings exhibited the structural fractures in the emergent inspection [2]. Generally, those spatial structures are utilized as evacuation shelters in the during- and post-disaster phases. However, they could not accommodate evacuees because of the safety reasons. This lesson learned implies the necessity of promoting the adequate seismic retrofitting for the relevant structures; and hence, the experimental investigation [3] [4] [5] [6] and analytical research [7] [8] [9] [10] had been accumulated in the Japanese society.

Most of those facilities consisted of RC frames and steel roofs assembled by anchor bolts at the column top. In addition, they possessed stiff gable ends filled with RC seismic walls. According to the report of Japan Organization of Advancing Construction Technology [2], the types of structural damages could be classified into: 1) connection failure at the column top, 2) concrete crack at the column base, 3) buckling of sub-truss, and 4) out-of-plane deformation of the seismic walls on gable ends.

In the field of seismic and structural engineering, it is fatefully important to secure the function of structures even after strong shakes, particularly those for utilized as the evacuation shelters. For this aim, the authors had continuously addressed the damage mechanism of the gymnasium building damaged by the GEJET [11] [12] [13]. On the other hand, our previous research implied that the presence of a slotted hole may cause the connection failure at less base shear by means of the stress concentration for the connection without slotted hole. However, previous literature [3]-[10] and our earlier research [11] [12] [13] have not addressed the various lengths of slotted hole. Therefore, the influence of slotted hole for the seismic capacity is still untouched in this field.

Based on the abovementioned discussion, this research conducts a comprehensive parametric study in terms of the length of slotted hole. The concerned structure is identical to our earlier research [11] [12] [13]. Through the pushover and seismic response analyses, this research summarizes the complex behavior and influence of slotted hole for the connection failure and damage of RC column. This research aims to provide the fundamental data of the seismic risk of similar types of structures to the international platform.

\section{Outline of Analyses}

\subsection{Framework of Analyses}

In this paper, the eigenvalue analyses, pushover analyses, and seismic response analyses are demonstrated to investigate the seismic capacity in the static and 
dynamic manners.

The eigenvalue analyses are conducted to understand the characteristics of vibration modes of the concerned structure. The pushover analyses are carried out for clarifying the fundamental structural behavior and damage mechanism. Also, in the practical design, the pushover analyses are generally performed by virtue of their simplicity and time efficiency. Therefore, this research accumulates the analytical results to be compared with those by the seismic response analyses. The seismic response analyses are demonstrated to precisely quantify the slotted hole effect caused by the complex vibration modes and resonance. In further, the expected gap between the pushover and seismic response analyses can be investigated based on the obtained results in this article.

The floor plan and details of the connection at the column top are, respectively, illustrated in Figure 1 and Figure 2. The concerned structure exhibited the connection failure presented in Figure 3 and concrete crack due to the bending moment. Our previous research [13] revealed that there was a damage mechanism issued from the discrepancy of horizontal stiffness between the gable end and center shore. In further, the obtained results agreed well with the actual damage [13].

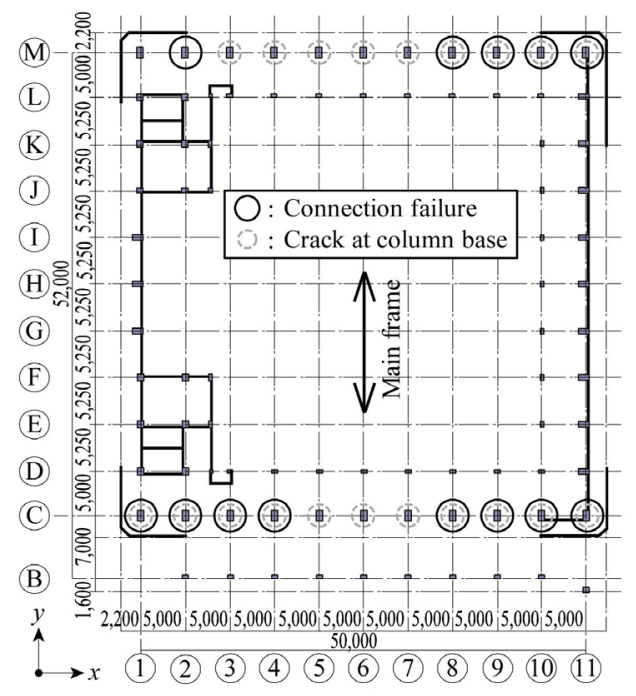

(a)

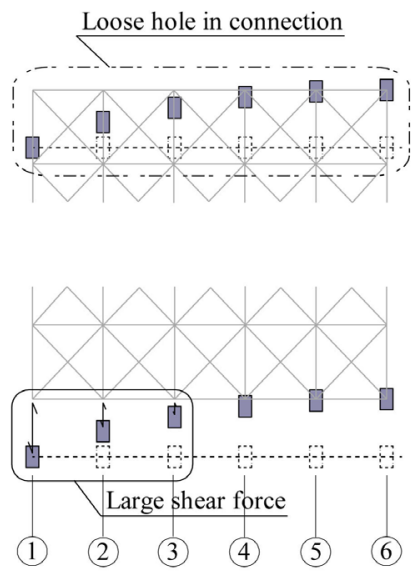

(b)

Figure 1. Floor plan and location of structural damages. (a) Floor plan; (b) Damage mechanism [13].

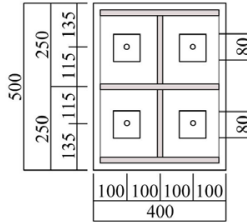

(a)

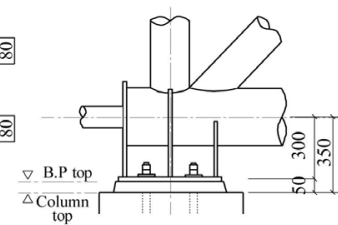

(b)

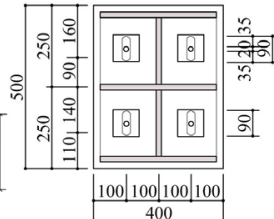

(c)

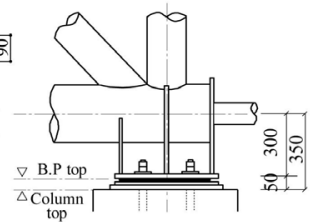

(d)

Figure 2. Details of connection at column top. (a) Shore-C (plan); (b) Shore-C (elevation); (c) Shore-M (plan); (d) Shore-M (elevation). 


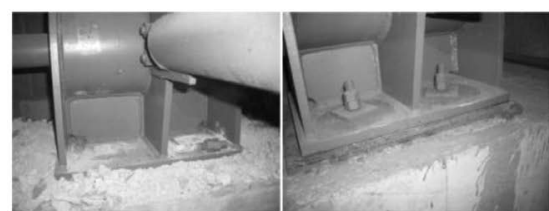

(a)

(b)

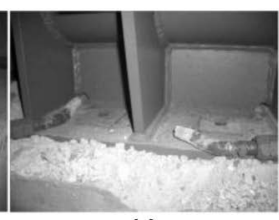

(c)

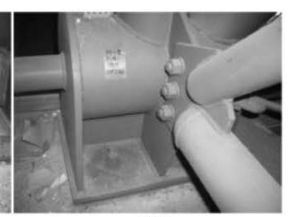

(d)

Figure 3. Typical connection failure. (a) $1 \times \mathrm{C}$ connection; (b) $1 \times$ Mconnection; (c) $3 \times$ C connection; (d) $3 \times$ Mconnection.

\subsection{Details of Analysis Model}

Figure 4 illustrates the analysis model. A series of analyses are carried out by ABAQUS 6.14 [14], a finite element analysis software package. This research assumes the symmetricity of the structure and analyzes half of the frame as same as the earlier research [11] [12] [13].

Figure 5 illustrates the configuration and mass distribution of respective shore. The seismic walls in Shore-1 are modelled by braces.

The hysteresis of truss members is the bi-linear with the second modulus of $k / 1000$, where $k$ is the initial stiffness. However, it had been confirmed that they remained within the elastic range in this series of analyses. In terms of RC members, the trilinear model comprised the crack moment, $M_{\mathcal{c}}$ and the ultimate bending moment, $M_{u}$, is assumed. To realize precise analyses, strengths of RC members are calibrated based on the finite element analyses on the respective $\mathrm{RC}$ columns and beams.

The shear hysteresis of column top connection is determined as Figure 6(a). In the Shore- $\mathrm{C}$, the connection possesses the bi-linear hysteresis, while Shore-M performs the slip-bilinear hysteresis due to the presence of slotted hole. Hereinafter, the analysis with the slotted hole length of $d_{l}$ (unit: millimeter) is designated as $\mathrm{LH}-d_{1}$ in this research. In addition, this research covers from $\mathrm{LH}-0$ to LH-140. The initial stiffness is determined referring the previous experiment [15]. The second modulus is assumed as $k_{s} / 1000$. The ultimate shear strength, $Q_{u}$, is calibrated based on the ultimate tensile strength and shape factor of anchor bolts.

Regarding the moment-rotation relationship, the bi-linear hysteresis is assumed as depicted in Figure 6(b). The rotational stiffness, $k_{r}$, and strength, $M_{u}$, are calibrated in conformity to the guideline for the exposed column bases [16].

In this series of analyses, the connection reaches the ultimate shear strength prior to the ultimate bending strength. Therefore, this research judges the failure at which the shear force of the column top exceeds the ultimate shear strength, $Q_{u}$.

\subsection{Outline of Pushover Analyses}

The external force is vertically distributed in accordance with AIJ's recommendation [17]. In addition, the magnitude of base shear is horizontally distributed based on the weight of respective shore. The load distribution is indicated in Figure 4 . 


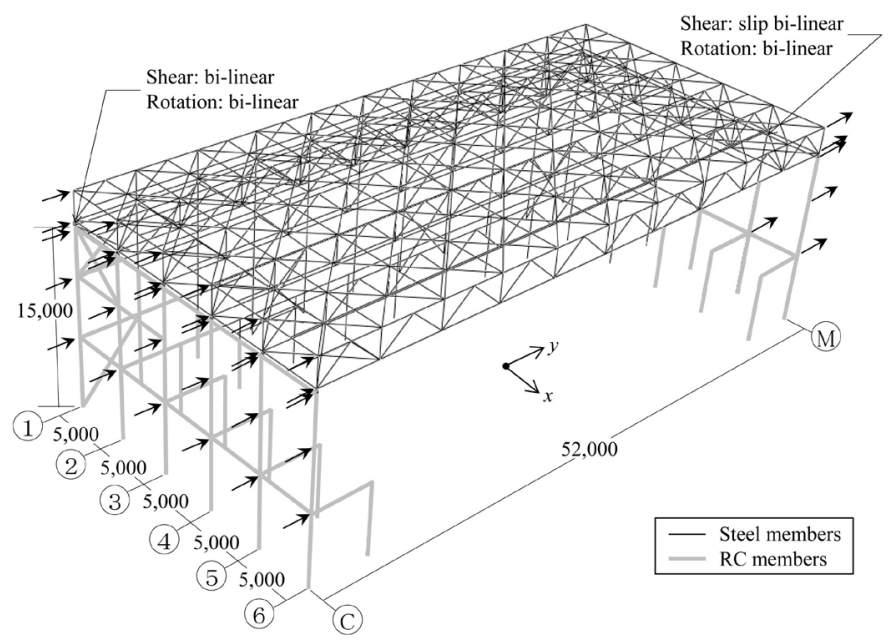

Figure 4. Analysis model.

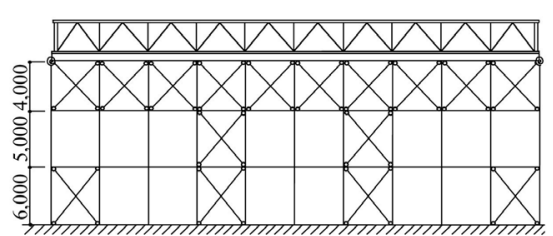

(a)

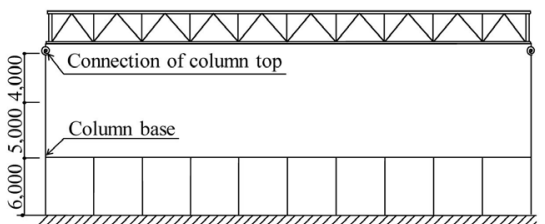

(c)

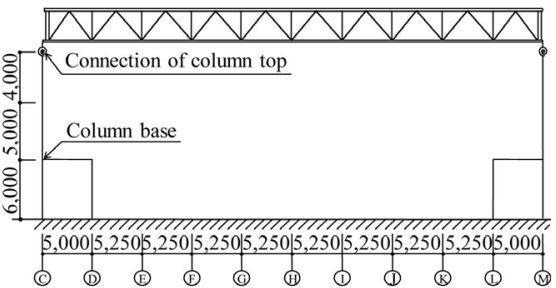

(e)

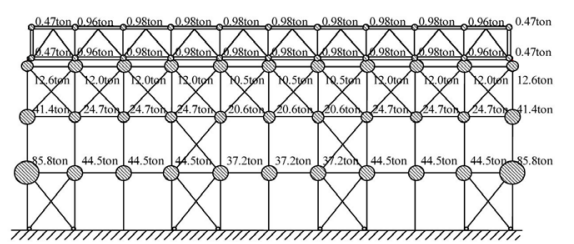

(b)

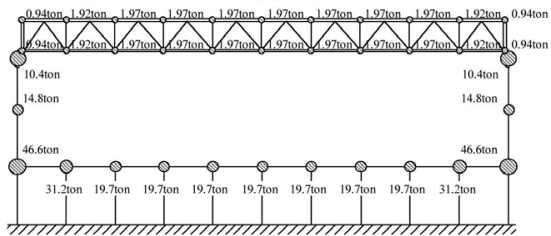

(d)

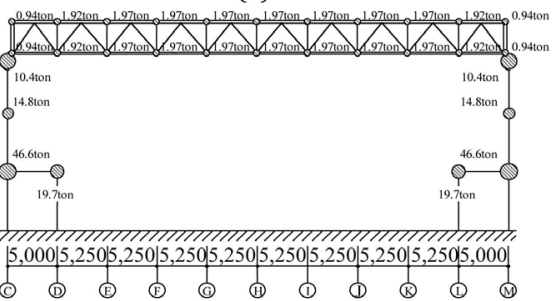

Figure 5. Configuration of analysis models. (a) Configuration (Shore-1); (b) Mass distribution (Shore-1); (c) Configuration (Shore-2); (d) Mass distribution (Shore-2); (e) Configuration (Shore-3 to -6); (f) Mass distribution (Shore-3 to -6).

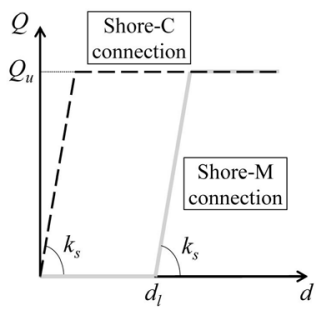

(a)

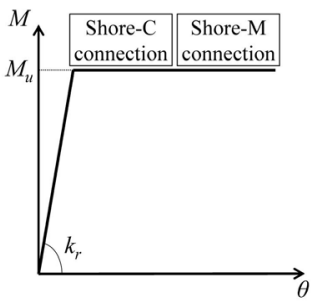

(b)

Figure 6. Hysteresis of connection at column top. (a) Shear-displacement; (b) Moment-rotation. 


\subsection{Details of Seismic Response Analyses}

In the seismic response analyses, Rayleigh damping is adopted for each structural member. The primary and secondary damping ratios are, respectively, 5\% for RC members and $2 \%$ for steel members.

The input wave was recorded on March 11th in 2011 at National Institute of Technology, Sendai College, located $1.5 \mathrm{~km}$ apart from the concerned building. The NS-direction is utilized as same as the previous research [13].

\section{Eigenvalue Analyses}

Figure 7 illustrates the primary and secondary modes of the structure. In the primary mode, the steel roof and $\mathrm{RC}$ frame in Shore-C deforms horizontally, whereas the RC frame in Shore-M does not present the displacement. In the meantime, the secondary mode exhibits the horizontal displacement of Shore-M only. The natural periods of primary and secondary modes are, respectively, $0.456 \mathrm{sec}$ and $0.317 \mathrm{sec}$. In further, it can be confirmed that the horizontal displacement tends to become larger from the gable end (Shore-1) to the center frame (Shore-6).

\section{Pushover Analyses}

\subsection{Damage Process of Reference Case (LH-35)}

In this section, the analytical results of LH-35, which corresponds to the actual slotted hole length, are summarized as a reference case. Figure 8(a) and Figure 8 (b) indicate the relation between the shear force of column top connection, $Q$, and deflection angle of column at $6 \times \mathrm{C}, \delta / h$. Here, $\delta$ denotes the horizontal displacement of column top and $h$ designates the height of the column $(=15,000$ $\mathrm{mm})$. Also, $6 \times \mathrm{C}$ means the location of Shore- 6 versus Shore-C. Hereinafter, $x \times$ $y$ represents the place of the Shore- $x$ ( $x$-direction) versus Shore- $y$ ( $y$-direction). In addition, $\nabla$ and $\boldsymbol{\nabla}$, respectively, indicate the connection failure at the Shore-C and Shore-M.

As described in Figure 8(a), the connection of Shore-1 originates the failure at $\delta / h=0.0009 \mathrm{rad}$. After the connection failure at Shore-1, the shear force of Shore-2 begins to increase rapidly. This is because Shore-2 receives larger restraint from Shore-1 by the RC beams. Eventually, the connection failure occurs from the gable end side by means of the identical damage mechanism.

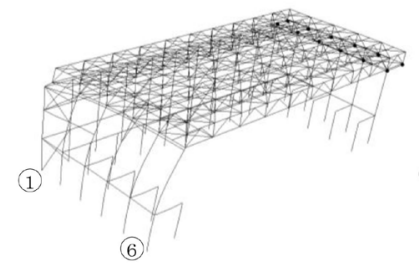

(a)

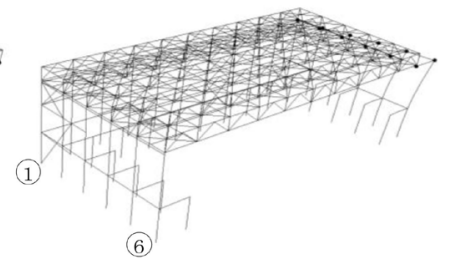

(b)

Figure 7. Deformation of primary and secondary modes. (a) Primary mode $(0.456 \mathrm{sec})$; (b) Secondary mode $(0.317 \mathrm{sec})$. 


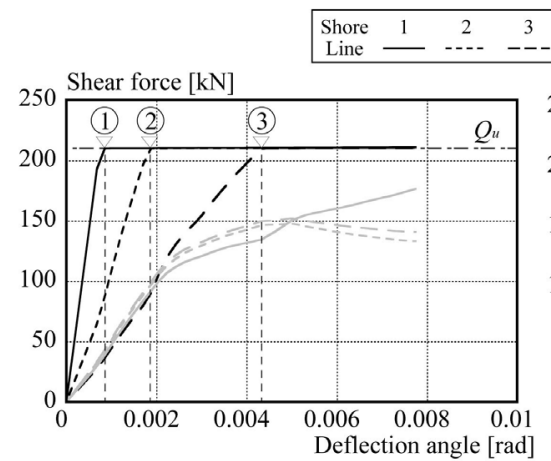

(a)

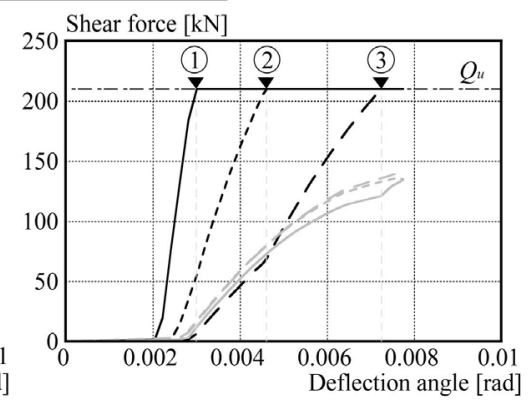

(b)

Figure 8. Shear force-deflection relation obtained by pushover analysis. (a) Shore-C; (b) Shore-M.

Regarding Shore-M illustrated in Figure 8(b), the shear force begins to enlarge at around $\delta / h=0.002 \mathrm{rad}$, and the connection failure is originated from Shore-1. Subsequent connection failure happens with the identical order with Shore-C.

Figure 9 exhibits the relation between the bending moment at the column base of 2nd story and deflection angle of the column in Shore- 6 . The crack moment, $M_{\mathcal{c}}$ and ultimate bending moment, $M_{u}$ are depicted in Figure 9. In Figure 9(a), the discrepancy of bending moment is not prominent among $3 \times \mathrm{C}$ to $6 \times \mathrm{C}$ and the column base reaches the ultimate bending strength at an almost identical deflection angle of connection failure of $3 \times \mathrm{C}$.

In respect with Shore-M exhibited in Figure 9(b), the bending moment rapidly enlarges from $\delta / h=0.0025 \mathrm{rad}$, at which the slip displacement of connection exceeds the length of slotted hole. The skeletons of Shore- 3 to Shore- 6 become almost identical, and reach the ultimate bending moment at an identical deflection angle of connection failure of $3 \times \mathrm{M}$.

\subsection{Influence of Length of Slotted Hole for Structural Capacity}

The relation of base shear, $Q / W$, and deflection angle, $\delta / h$, is indicated in Figure 10 (a). Here, $Q$ is the sum of applied shear force and $W$ is the total weight of the structure. The deflection angle of rapid stiffness enlargement differs considerably depending on the length of slotted hole. In Figure 10(a), the connection failure is indicated in the case of LH-35.

Figure 10(b) illustrates the transition of base shear at which the connection failure occurs arranged by the length of slotted hole. In LH-0, largest base shear is demonstrated because Shore- $\mathrm{C}$ and Shore-M resist the external force in parallel. With an increase in the length of slotted hole, the base shear at the connection failure decreases; and eventually, it converges in LH-70. The base shear drops up to almost $50 \%$ when the length of slotted hole becomes long enough.

The slotted hole needs to be settled for absorbing the construction error and heat shrink and expansion. However, this deterioration of seismic capacity should be noted among structural engineers and researchers. 


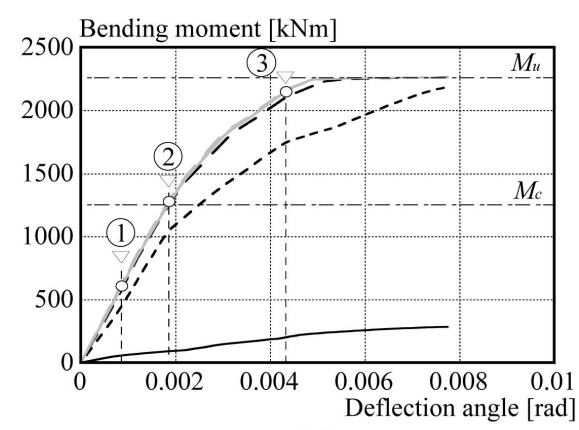

(a)

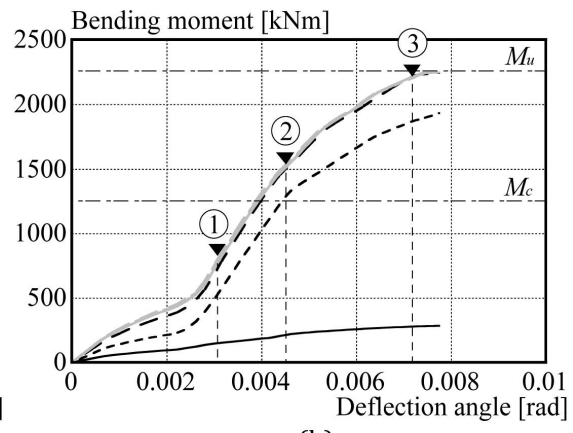

(b)

Figure 9. Bending moment-deflection relation obtained by pushover analysis. (a) Shore-C; (b) Shore-M.

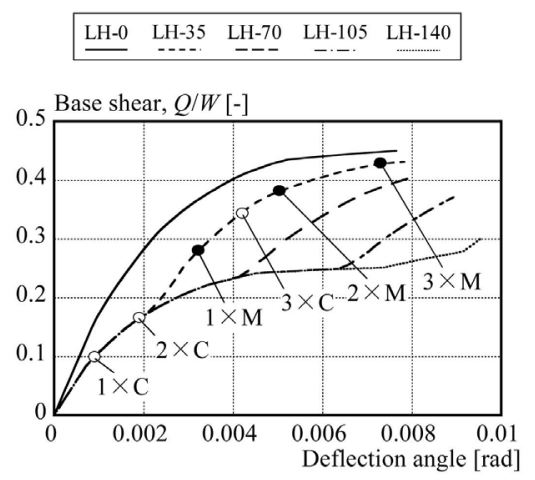

(a)

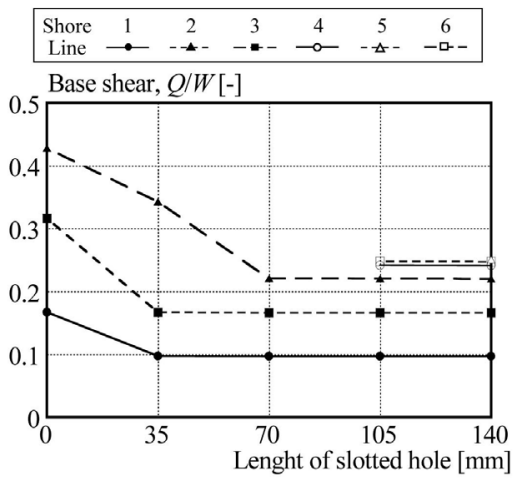

(b)

Figure 10. Influence of length of slotted hole for base shear at connection failure. (a) Base-shear-deflection relation; (b) Base shear at connection failure.

\section{Seismic Response Analyses}

\subsection{Influence of Slotted Hole Length for Displacement of Column Top}

Figure 11(a) and Figure 11(b), respectively, indicate the maximum displacement of column top in Shore- $\mathrm{C}$ and Shore-M arranged by the length of slotted hole.

In Figure 11(a), the maximum displacement is measured in Shore-6 in all cases. Within the range of series of analyses, smallest displacement is performed in LH-17.5, while largest one is originated in LH-26.25. This fluctuation is inferred to be caused by the resonance with the seismic wave. The horizontal displacement of Shore- 3 to Shore- 6 gradually converges into about $43 \mathrm{~mm}$ in longer lengths of slotted hole.

In Figure 11(b), within the slotted hole length of $0 \mathrm{~mm}$ to $17.5 \mathrm{~mm}$, the maximum displacement is negatively proportional to the length of slotted hole. However, in longer lengths of slotted hole, the displacement tends to decrease in Shore-2 and Shore-3, whereas it gradually enlarges in Shore-4, Shore-5, and Shore-6. This is explainable by the following mechanism.

In Shore-2 and Shore-3, the frames receive larger restraint from Shore-1, 


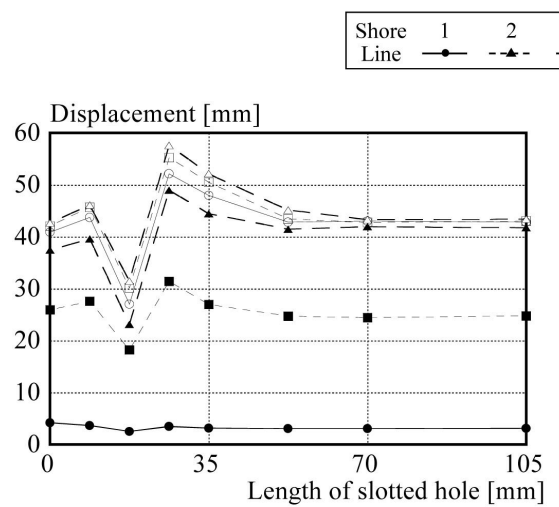

(a)

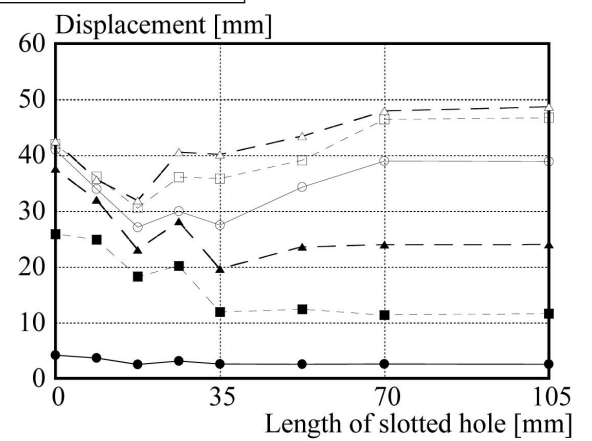

(b)

Figure 11. Influence of length of slotted hole for maximum horizontal displacement. (a) Shore-C; (b) Shore-M.

which is filled with the seismic walls. In addition, the inertia force is not carried from the steel roof due to the longer length of slotted hole. The maximum displacement in Shore-2 and Shore-3, therefore, becomes smaller in longer slotted hole length. Regarding Shore- 4 to Shore- 6 , the RC column receives less restraint from the gable end; and eventually, the secondary mode depicted in Figure 7(b) prominently appears during the excitation. Moreover, the vibration as a cantilever is not confined by the steel roof. Hence, the different characteristics among the shores are demonstrated depending on the slotted hole length.

\subsection{Influence of Slotted Hole Length for Shear Force of Column Top Connection}

Figure 12(a) and Figure 12(b) illustrate the relation between the maximum shear force of column top connection and length of slotted hole.

In Figure 12(a), the shear force reaches the ultimate shear strength in Shore-1 and Shore-2 regardless of the length of slotted hole. Figure 12(a) proves that the identical damage mechanism revealed in the earlier research [13] and the previous chapter is demonstrated in the dynamic analyses.

In LH- 0 , the connection failure does not occur from Shore- 3 to Shore- 6 by virtue of the contribution of Shore-M resisting the applied shear force in parallel.

In LH-17.5, the connection of Shore- 5 and Shore- 6 reaches the ultimate shear strength. This value is almost twice of the one in LH-0. In the pushover analysis summarized in the former chapter, the connection failure occurred from the gable end side; however, the connection failure in Shore- 6 appears prior to Shore-3 and Shore- 4 in the seismic response analysis.

In larger slotted hole length, the shear force in Shore-3 gradually enlarges; and eventually, the shear force reaches the ultimate shear strength in LH-35. In this series of analysis, Shore- 4 does not originate the connection failure.

On the other hand, all connections in Shore-M reach the ultimate shear strength in LH-17.5 and LH-26.25. The relief of shear force occurs from Shore-2 


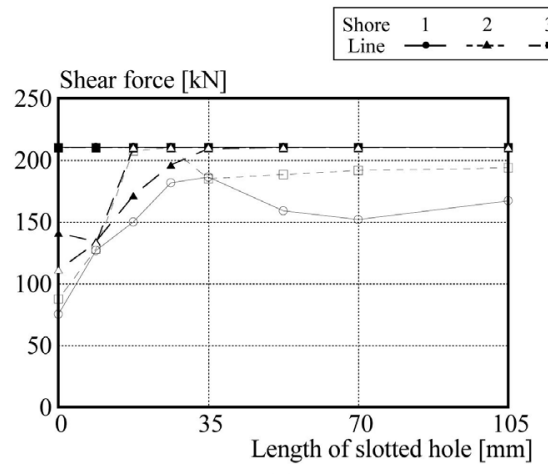

(a)

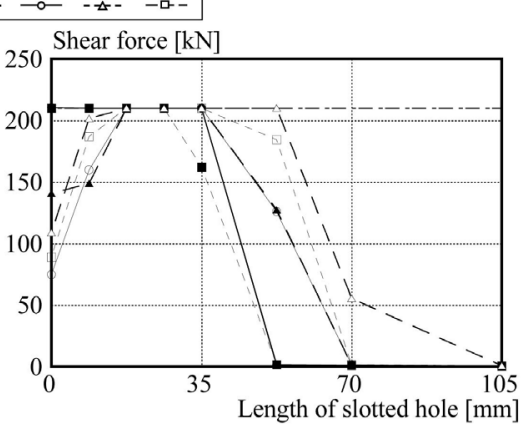

(b)

Figure 12. Influence of length of slotted hole for shear force. (a) Shore-C; (b) Shore-M.

in LH-35. In longer lengths of slotted hole, all connections firstly remain within the elastic range in LH-70, and the connections do not carry the shear force in LH-105.

In Figure 12(b), the large shear force of center frame in LH-8.75 to LH-35 is inferred that there is a different mechanism in the dynamic analyses.

Figure 13 indicates the time-history response of Shore- 6 in LH-35. The duration is extracted from $30 \mathrm{sec}$ to $40 \mathrm{sec}$, at which the first main shock strikes the structure. In Figure 13(a), it can be confirmed that the vibration phase of Shore-C and Shore-M differs each other, which proves the independent shake among the shores. This gap causes the collision between the anchor bolts and edge of slotted hole. Hence, as indicated in Figure 13(b), the shear force exhibits rapid enlargement; and eventually, this pulse originates the connection failure.

This collision effect cannot be modelled in the static analyses; therefore, a particular attention is necessary to conduct the seismic diagnosis and strengthening adequately.

\subsection{Influence of Slotted Hole Length for Maximum Bending Moment at Column Base}

Figure 14 indicates the relation between the maximum bending moment at column base and length of slotted hole. In Figure 14(a), the maximum bending moment is almost consistent regardless of the slotted hole length. In addition, the bending moment is almost identical among Shore-3 to Shore-6, which corresponds to the results of the pushover analyses.

In Figure 14(b), the maximum bending moment presents the similar trend with that in Figure 11(b). This is because the previously stated unique mechanism in the dynamic analyses also affects the bending moment of the column base.

The above discussion corroborates that the presence of a slotted hole causes the discrepancy between the results obtained from the static and dynamic analyses. The structural engineers and researchers are strongly recommended to devote the attention to this phenomenon for preventing the unexpected structural damage and keeping the function of critical facilities even after huge earthquakes. 


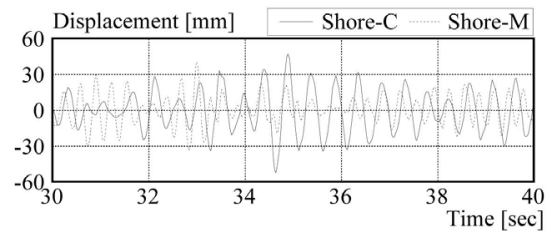

(a)

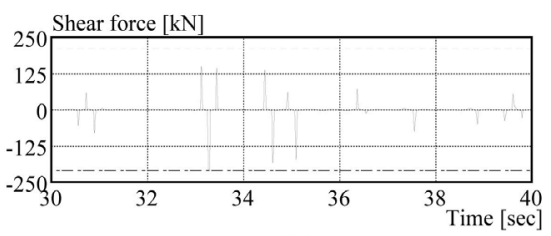

(b)

Figure 13. Time-history response of displacement and shear force. (a) Displacement; (b) Shear force.

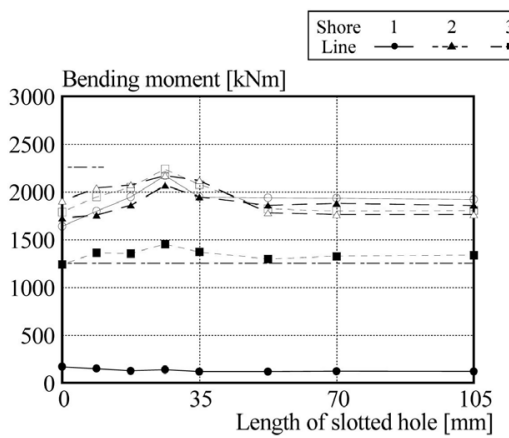

(a)

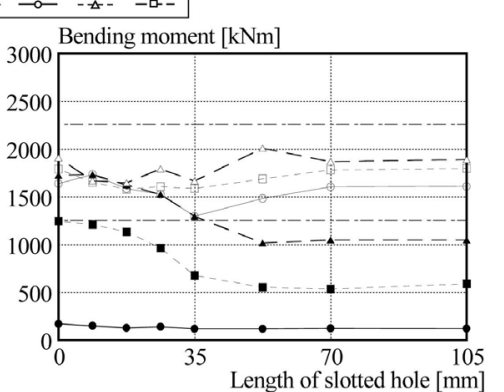

(b)

Figure 14. Influence of slotted hole for bending moment at column base. (a) Shore-C; (b) Shore-M

\section{Conclusions}

This research carried out the pushover analyses and seismic response analyses to reveal the influence of the slotted hole length for the damage mechanism. The remarkable findings are summarized as follows.

1) The slotted hole originates the lag until the connection performs the shear force. Therefore, the connection without slotted hole possibly fails before the one with slotted hole begins to resist the shear force.

2) The connection with slotted hole can fail by the rapid enlargement of shear force by means of the collision between the anchor bolts and slotted hole edge.

3) The presence of a slotted hole makes significantly different characteristics between the static and dynamic analyses. The simple method to reflect the slotted hole effect is highly demanded to bridge this discrepancy.

In the future research, the authors will propose and verify the damage prevention design method of slotted hole through generalizing the relevant types of structures.

\section{Acknowledgements}

This research was funded by SECOM Science and Technology Foundation (Principal Investigator: Prof. Yoshihiro Kimura). We express our deepest gratitude for the sincere cooperation.

\section{Conflicts of Interest}

The authors declare no conflicts of interest regarding the publication of this paper. 


\section{References}

[1] Joint Editorial Committee for the Report on the Great East Japan Earthquake Disaster (2014) Report on the Great East Japan Earthquake Disaster-Building Series Volume 3 Structural Damage to Steel Buildings and Structural Damage to Shell and Spatial Structures. Architectural Institute of Japan. (In Japanese)

[2] Japan Organization of Advancing Construction Technology (2015) Guideline of Seismic Diagnosis and Strengthening of RC Frame with Steel Roof. Gihodo Shuppan Co. Ltd., Tokyo. (In Japanese)

[3] Inaba, Y., et al. (2018) Cyclic Loading Tests on Steel Roof Bearings and Effects on Roof Responses. Journal of Structural and Construction Engineering (Transactions of AIJ), 83, 1129-1137. (In Japanese) https://doi.org/10.3130/aijs.83.1129

[4] Ito, K., Yamashita, T. and Watanabe, S. (2019) Cyclic Shear Loading Test and Strength Evaluation on Roof Bearings. Journal of Structural and Construction Engineering (Transactions of AI), 84, 649-657. (In Japanese) https://doi.org/10.3130/aijs.84.649

[5] Yamashita, T. and Wada, N. (2019) Study on Stability in Sliding of Bearings Supporting Large-Span Steel Roofs. Journal of Structural and Construction Engineering (Transactions of AIJ), 84, 1251-1258. (In Japanese) https://doi.org/10.3130/aijs.84.1251

[6] Shimada, Y., et al. (2020) Method of Reinforcement for Joints between Steel Roofs and RC Columns in Existing Buildings. Engineering Structures, 209, Article ID: 110255. https://doi.org/10.1016/j.engstruct.2020.110255

[7] Narita, K., Takeuchi, T. and Matsui, R. (2013) Seismic Performance of School Gymnasia with Steel Roofs Supported by Cantilevered RC Wall Frames. Journal of Structural and Construction Engineering (Transactions of AIJ), 78, 1895-1904. (In Japanese) https://doi.org/10.3130/aijs.78.1895

[8] Terazawa, Y., et al. (2015) Damage Control of Composite Gymnasium Structures with Energy-Dissipation Roof Bearings. Eighth International Conference on Behavior of Steel Structures in Seismic Areas, Shanghai, 1 June 2015, Paper ID 52.

[9] Kimura, T., Ohsaki, M. and Sato, K. (2020) Structural Optimization of Supporting Structure of School Gymnasium with Steel Roof for Seismic Response Reduction of Bearing Reaction Forces. Journal of Structural and Construction Engineering (Transactions of AIJ), 85, 61-71. (In Japanese) https://doi.org/10.3130/aijs.85.61

[10] Watanabe, S. and Yamashita, T. (2020) Earthquake Response Analysis of Steel Roof Gymnasiums Considering Nonlinear Restoring Force Characteristics of Lower Structure and Roof Bearings. Journal of Structural and Construction Engineering (Transactions of AI), 85, 209-218. (In Japanese) https://doi.org/10.3130/aijs.85.209

[11] Fujita, T., et al. (2014) Damage Investigation and Analysis of Damage Mechanism on Spatial Structure Consisted of Steel Roof and RC Substructure. Proceedings of JCI Annual Conference, 36, 1297-1302. (In Japanese)

[12] Fujita, T., Suzuki, A. and Kimura, Y. (2014) Static Elasto-Plastic Analysis for Damage Mechanism of Gymnasium Structured RC Frame with Steel Roof Structure. Proceedings of Constructional Steel, 22, 447-452. (In Japanese)

[13] Suzuki, A., Fujita, T. and Kimura, Y. (2016) Damage Mechanism of Gymnasium Building with RC Frame and Steel Roof Damaged by the 2011 Tohoku Earthquake. Journal of Steel Construction, 23, 17-29. (In Japanese)

https://doi.org/10.11273/jssc.23.91_17 
[14] Dassault Systèmes (2014) Abaqus 6.14 Online Documentation. Dassault Systèmes.

[15] Kato, H., et al. (2010) Tensile Test and Shear Test of Improved Type of Reinforced Anchor-Bolts-A Study on Improving Plastic Deformation Capacity of Anchor-Bolts in Exposed Column Bases of Existing Steel Buildings Part 2. Journal of Structural and Construction Engineering (Transactions of AI), 655, 1709-1716. (In Japanese) https://doi.org/10.3130/aijs.75.1709

[16] Architectural Institute of Japan (2012) Recommendation for Design of Connections in Steel Structures. Maruzen Publishing Co. Ltd., Tokyo. (In Japanese)

[17] Architectural Institute of Japan (2015) Recommendations for Loads on Buildings. Maruzen Publishing Co. Ltd., Tokyo. (In Japanese) 